\title{
Theoretical basis of the psychoanalytic approach to psychotherapy of autism
}

\begin{abstract}
In the modern scientific and professional environment psychoanalytic psychotherapy is placed in the background regarding its possibilities in the treatment of autism. This position, expressed by the question of possibilities of its use in the therapy of autism, is identified by the author as a result of the existing dichotomy ('splitting') in 'organic' and 'psychic' concepts of its etiology. To overcome the above constraint the author, on the base of his twenty years of psychotherapeutic experiences with eight autistic children, suggests the possibility of developing such concept of autistic psychogenesis and based on it a therapeutic approach. In support of his therapeutic observations, in this article were used contributions of contemporary researches by intersubjectivists, whose results speak in favour of the thesis.
\end{abstract}

Volume 2 Issue 2 - 2015

Aldo Spelic
University of Juraj Dobrila in Pula, Croatia

Correspondence: Aldo Spelic, Nazorova 4, Pula 52100, Croatia, Tel 38552382077, Email aldo.spelic@gmail.com

Received: January 20, 2015 | Published: February 04, 2015

\section{Introduction}

Ladies and gentlemen, dear colleagues, I am glad to have this opportunity to present some parts of my concept of psychoanalytic psychotherapy of autism developed over the past twenty years of my psychotherapeutic practice with eight autistic children. Psychoanalytic psychotherapy of autism as a topic has very little presence in modern theoretical and practical discussions, what is also evident in contemporary literature review of a small number of articles dealing with this issue. This state is evident in the fact presented by Louise Ruberman ${ }^{1}$ that the contemporary scientific and professional debates about psychoanalytic psychotherapy of autism are mainly reduced to the question of its historical role in the development of treatment of autism. Therefore, today we can see that in scientific and professional environment the psychoanalytic psychotherapy is placed in the background regarding contemporary approaches to the therapy of autism.

This position of psychoanalysis and other psychodynamic approaches in the treatment of autism, from Rubeman's point of view, ${ }^{1}$ may be explained by modern scientific trends that are dominated by neuroscience and genetics. These trends are recognized by Fonagy ${ }^{2}$ within contemporary American psychiatry where the struggle for power and control between biological and psychoanalytic psychiatry is present. Through this conflict within the modern scientific and professional environment which has been under influence of pharmacological companies, especially at the beginning of the XXI century, in the period of the so-called 'decade of brain', significant changes have occurred in the understanding of the causes of mental illness. So today, in the explanation of mental disorders we encounter a change from psycho-dynamic towards constitutional theories of the mental illness etiology. This shift is equally present in the therapeutic approach from former long-term psychotherapy to current long-term pharmacological and short-term psychological therapy, mainly behavioral-cognitive ones.

According to these observations, in the spirit of this new trend in the scientific and professional environment, we are faced with the definition of autism as an organic disorder. Thus, referring to the DSMIV and ICD-10 on the website of Autism Europe (AE) ${ }^{3}$ we find the definition of autism as a "pervasive developmental disorder of brain functions which prevents a person from organizing and understanding information that affects social interactions." Starting from this understanding of autism as a consequence of significant brain damages which are important in psychosocial functioning, there is very little room for psychotherapeutic activities. In such scientific and professional environment, it is quite clear that psychoanalytic and any other psychotherapeutic approaches (as cognitive-behavioral ones) may have only limited significance and applicability in the treatment of autism. ${ }^{1}$

Therefore, at the beginning of this presentation of the psychoanalytic psychotherapy of autism it is necessary to deal with the issue of possibilities of psychoanalytic or any other approaches to the psychotherapy of autism. The issue of these possibilities is closely connected with the question of the possibility of constructing a model of psychic genesis of autism. To represent this possibility of building such a model necessary for psychotherapeutic successfulness, I will use my experiences from psychotherapies with autistic children in the past twenty years in which I was confronted with certain restrictions which I have gradually overcome, step by step.

At the beginning of my psychotherapeutic work with an autistic girl Martina, I was faced with the same understanding of autism as an organic disease. Therefore I set then very limited psychotherapeutic goals that I have widened only later gradually with some positive therapeutic achievements. So the initial goal was to help the autistic girl overcome difficulties in her adjustment to some psychosocial conditions. However later goals were widened in a way to overcome certain autistic symptoms themselves. Just these changes in my therapeutic goals connected with overcoming some therapeutic constraints and difficulties led me to the gradual development of the concept of psychoanalytic psychotherapy of autism which I will speak about in this lecture.

Therefore in this presentation the emphasis will be on some constraints and difficulties which I was confronted with during my psychotherapy with eight autistic children and on their overcoming that has determined the frame of this concept of psychoanalytic psychotherapy of autism. This concept was presented for the first time on the $1^{\text {st }}$ Croatian Congress of Psychotherapy in Zadar ${ }^{4}$ after my previous fifteen years of therapeutic work with autistic children.

\section{First psychotherapy with autistic child Martina}

Now I will start the presentation of this concept by showing some experiences related to my initial psychotherapies with autistic children. The first psychotherapy with an autistic child, I started twenty 
years ago at the beginning of my private practice, after my previous sixteen years of employment at the psychiatric ward at the general hospital in Pula. In this period I finished my training in individual psychotherapy and obtained status of a supervisor of psychoanalytic psychotherapy. In 1993 I met for the first time the autistic girl Martina, who was diagnosed autistic disorder in her third year. At that time the girl had not yet developed speech, she looked affectively absent together with the presence of many stereotyped, ritualistic behaviours and grimaces. She showed no interest in other people in her surrounding and in an attempt to establish a relationship she reacted with anxiety and withdrawal.

In the period prior to the arrival to a therapy, her parents did nothing due to the information received from various experts that their daughter had a severe organic damage that, in the future, would disable her to develop cognitive functions and speech and to form social relations. Her mother was said that her daughter would never be able to utter 'mom' in contact with her neither to be educated nor to develop any social relation. As such the girl was included in the preschool where the stuff had "no problem" with her, because she, except affective withdrawal, did not show any excessive states of anxiety or aggression. 'Problems' started with her integration into a regular elementary school when confronted with a new environment she started to express high level of anxiety accompanied by unusual forms of behaviour as screaming, hiding and escape from classroom. Based on the occurrence of these behaviours, school professionals initiated the procedure of moving the girls into a specialized institution which prompted her parents to turn for help.

According to the mother's statement, her pregnancy, childbirth and subsequently psychomotor development of the girl in the first year of life were normal. Among the multitude of information that the mother stated the fact that the girl at the end of the first year of life was suddenly hospitalized for ten days following one unfortunate incident in which the she was burned due to negligence of her caregiver, drew my attention. Then I recognized possibility that this experience of hospitalization might have produced some delay in her development. During my working through his event parents recognized that then after her return home from the hospital they might have noticed some minimal changes in their child's behaviour such as apathy, withdrawal and psychomotor slowness.

In a situation of making a decision to start a psychotherapy with the girl regarding the generally accepted concept of autism as an organic disease I had a dilemma whether psychotherapeutic approach could produce any positive changes in her autistic condition. Such a task, then, looked like an 'impossible mission or venture' and therefore I set a very limited psychotherapeutic goal. It was to help the girl gain control over her state induced by her bad experience in integration into a regular elementary school.

After establishing a visual contact and gradually increasing her affective involvement, her new state was followed by positive changes (considering her initial difficulties) in adjustment to a new school environment. These changes led me to widen my initial therapeutic task. The fact of the existence of separation trauma during her early development gave me an impetus to accept psychotherapy, namely to put the symptoms of autism in the center of the therapeutic interest. Then I understood autism as many psychotherapists today, in accordance with the concepts of Melany Klein, ${ }^{6}$ Margaret Mahler, ${ }^{7}$ John Bowlby, Rene Spitz, ${ }^{9}$ Donald Winnicott ${ }^{10}$ as a result of early traumatic separation experiences during the child's development of object relations.

Having established a good therapeutic relationship with the au- tistic girl, gradual changes followed in relation to her initial autistic conditions. Thus, with the development of the therapeutic relationship and the emergence of the first forms of imitation and subsequently internalization, this new state was followed by a gradual development of certain mental structures expressed by such achievements as the emergence of speech, interest in social environment and withdrawal of stereotyped behaviours. All of these changes were followed by a positive change in her cognitive abilities as well as the ability of adoption of certain school contents.

During the therapeutic work with Martina changes were obtained in all areas of her psycho-social functioning, especially those in cognitive field. The girl who was initially diagnosed as a mentally retarded person, without any possibility to form a verbal and social development, today at twenty-eight she has a lower-average or slightly below-average level of intellectual functioning. During her education she gained a title of assistant tailor. Today she lives with her parents and travels daily to work in another city. At work, she has developed good affective relationships with other employees. Today, in addition to being involved in individual psychotherapy once a week, she attends group-analytic sessions for young people led by my colleague.

These positive results with Martina encouraged me to gradually include into therapy other autistic children. ${ }^{11}$ In these therapies with eight autistic children I have gained many insights into autism that have played an important role in the development of the concept, of which one part will be discussed in this lecture. New findings having shed new light on the importance and the role of early development in the genesis of autism significantly influenced changes in the therapeutic approach. These findings have enabled me, as I have already said before, to expand the therapeutic goals.

Through this short presentation it may be noted that this concept has been gradually created by overcoming constraints faced during my psychotherapeutic work with eight autistic children. Having recognized the possibilities to overcome constraints I was encouraged to investigate new therapeutic possibilities and develop this new psychogenetic concept of autism. Therefore, in the presentation of some parts of this concept I will start from constraints and their overcoming important for the treatment of autism.

The first constraint has already been noted in the previous presentation of modern trends in scientific and professional environments. These trends, which are based on understanding autism as an organic disease, bring into question the psychotherapeutic approach in the treatment of autism. Therefore the first part of the presentation will start with the question of the possibility of psychoanalytic psychotherapy approaches to autism as well as the question of overcoming possibilities of the existing dichotomy between organic and psychic conceptions of autistic etiology.

The second constraint I was faced with relates to some psychoanalytic concepts. In this part, it is important to emphasize that, although conceptions of object relations theorists had a significant positive impact on my initial psychotherapeutic work with autistic children, at the same time I have noticed some disadvantages, whose overcoming was necessary for the therapeutic success and development of this concept. This constraint related especially to the understanding of the role of early traumatic experience in genesis of autism, and connected to that, to the therapeutic task of 'reconstruction' of this traumatic experience in the therapeutic milieu. Such approach did not provide the insight into the role of underdeveloped psychic structures in the genesis of autism. Giving emphasis on underdeveloped mental structures important in the development of object relation, the previous 
therapeutic task was changed in the 'construction' of those aspects of experiences significant in the development of mental structures important for the development of object relations.

Overcoming the aforementioned constraints the importance of failure in the early development of mental structures in genesis of autism was recognized. Through a therapeutic process with autistic children it has been recognized that just the failure in the development of first mental structures could be responsible for the failure in the process of separation-individuation, ${ }^{12}$ i.e. in the process of self-object differentiation and object establishment. It is this failure of self-object differentiation and object establishment that represents a fundamental problem in the pathogenesis of autism.

During my psychotherapeutic work I was faced with the question of what structures determine the success of the process differentiation and establishment of object relations. Based on the therapeutic experiences, it was noticed that in the development of these primary mental structures an important role plays the early narcissistic experience. As a final result of all these insights, autism may be understood as a failure in the development of primary narcissistic structures whose developmental failure may particularly manifest itself in the period of separation-individuation, i.e. during overcoming a separation crisis in the process of establishing object relations.

To gain insight into this concept of psychogenesis of autism and on it based therapeutic approach it is necessary to deal with the initial constraint whose overcoming led to its formation.

\section{First constraint:Autism and splitting in contemporary science}

In the introductory part I have already pointed out the first constraint which, from my point of view, presents the main problem psychotherapists are confronted with in an attempt to apply psychoanalytic approach in the treatment of autism. The present understanding of autism in the modern scientific and professional environment as an organic disease (disorder of brain functions) leaves us very little room for psychotherapeutic approach in the treatment of autism. Namely, if the symptoms of autism are understood as consequences of various forms of brain damage, then it is not to be expected that the psychotherapeutic approach can achieve any significant changes in autistic children in the area of their basic symptoms of autism.

Previously presented short case review of psychotherapy with Martina refutes and questions the above conclusion. In fact, achieved positive changes in the field of basic autistic symptoms, such as the emergence of speech, social interests and cognitive abilities with withdrawal of stereotyped motor actions, indicate that appropriate psychotherapeutic approach may achieve positive changes in primary autistic symptoms, not only in some aspects of adjustment. These positive changes in the field of the basic autistic symptoms suggest that the question of etiology and treatment of autism should be approached in a different way from that it is done today in the modern scientific and professional environment.

Talking about autism today, it is important to note that, in regard to symptoms included in the syndrome of autism, there is at least partial agreement, but in regard to the question of the etiology of autism there is a complete disagreement among authors. In this way the question of the etiology of autism represents the main problem that psychotherapist encounter at the beginning of a therapy with autistic children. This problem was particularly present at the beginning of my psychotherapy with Martina.
Now I must note with regret that today, as at the beginning of my psychotherapeutic work with autistic children, we are placed in the same scientific and professional environment. We are confronted with unclear concepts of autistic etiology and accordingly with the possibility of psychoanalytic or any other psychotherapeutic approach to autism. In accordance with this, today as it was before, there is a dominant negative attitude toward such possibility. Therefore, it is important to begin this presentation of new possibilities in psychotherapy of autism with a debate of etiology of autism as a central question regarding possible applications of psychoanalytic or any other psychotherapeutic approach in the treatment of autism.

Speaking today about the etiology of autism it means to commit oneself to one of the two opposite, mutually exclusive theoretical models followed by different therapeutic approaches. So on one hand we have 'organic' approaches, with the emphasis on bio-chemical (genetic, immune and metabolic) and neurological-degenerative causes followed by the medication and behavioral therapeutic approaches. On the other hand we have 'psychological' approaches, predominantly psychoanalytic, with the emphasis on environmental (emotional) causes followed by psychotherapeutic approach to treating autistic children. This state in scientific and professional environment in an earlier invited lecture in Slovenia ${ }^{13}$ I called the 'problem of splitting' in scientific and professional environment.

The problem of splitting regarding the question of etiology has existed from the very beginning of the creation of the concept of autism. Kanner, in his presentation of the 'early infantile autism' in $A u$ tistic disturbances of affective contact (1943) gave an important observation about the lack of emotional warmth in parents of autistic children. Later in The problem of nosology and psychodynamics of children's autism ${ }^{14}$ he expanded it by understanding the impact of ' genuine lack of maternal warmth in the emergence of autism with a special emphasis on parental coldness, obsessiveness and mechanical type of relations.

$>$ Although, in many works that followed he indicated the contribution of parental personality characteristics and their behaviour in the occurrence of autism, but in later on Annual meeting of the Autism Society of America (1969) under influence of the development of the concept of 'refrigerator mother' and negative reactions in the social environment he changed his first attitudes and expressed the view of the wrong interpretation of his observations. Afterwards, he returned to the claim that autism is inherent inability of children to form a common, biologically determined emotional contact with people, and that autistic children are born with innate physical and intellectual disabilities.

A particularly negative meaning of the development of 'psychological' theories of autism had Bettelheim's concept of autism expressed in The Empty Fortress. ${ }^{15}$ According to it the emotional development of autistic children in their family environments was seen as an emotional experience of prisoners in concentration camps. A particularly negative connotation had his observation that autistic children should be separated from their families. Consequently, with this approach parents are faced with a sense of guilt for their children's autism that was the main obstacle in accepting such concept of autism.

This Bettelheim attitude about 'refrigerator mothers' played an important role in a generally present negative attitude towards psychoanalytic approach in the psychotherapy of autism and also towards the model of autistic psychogenesis. Precisely with this Bettelheim attitude, which encouraged parental guilt for their children's autism, we can identify a trend that has resulted in replacing psychoanalytic 
with behavioral approach in the treatment of autism. In the context of this trend, Watters ${ }^{16}$ recognized that the advantage of behavioral approaches in relation to the psychoanalytic ones in treatment of autistic children was that they

\section{A. Exclude the feeling of parental guilt and}

B. In their approach do not involve the question of etiology of autism.

This Watters observation suggests that the question of the etiology of autism, except for the question of parental guilt, represents the undesirable question from the standpoint of contemporary scientific and professional trends in the understanding of autism. However, we have to agree that without the answer to this question of etiology of autism neither therapeutic approach may be appropriate.

\section{Splitting in scientific approaches: 'Fact' and 'fiction' in the etiology of autism}

Elevating this problem of etiology of autism on the level of scientific value (scientific level) we can observe that the previously defined problem of splitting in understanding the etiology of autism was brought up to the level of absolute exclusivity. Therefore we can now recognize that the problem of splitting is being shown as a scientific problem. Thus, some authors like Herbert et al., ${ }^{17}$ require that, considering the question of the etiology of autism and approaches to its treatment, 'fact' from 'fiction' has to be separated.

For the above-mentioned authors 'facts' represent those investigation results based on the standards of a scientific methodology, primarily on control and randomized samples. In their methodology, there are investigations of differences between groups of autistic and control subjects on some variables, especially organic ones. On the basis of these investigation approaches, they strive to make conclusions about causal relationship between these variables and the occurrence of autism, which has no scientific validity of the 'causal facts'. This problem is very serious and deserves to be dealt with separately in some other article. In contrast to these 'facts', all other findings made on the basis of observations through a therapy or any other investigation approaches represent for them 'fictions' and as such must be rejected as unreal.

In the analysis of the obtained results ('facts') authors themselves observe that most of these investigations do not fully meet the standards imposed by science methodology. This is expected because the subject of investigation with its complexities does not give us possibilities to control all relevant variables which are present in making conclusion about causality. A particular problem represents results ('facts') which indicate different neuro-biological and genetic variables. ${ }^{18-25}$ Such results represent mutually unrelated, inconsistent and divergent 'facts'.

The results of this approach, which bring unrelated, inconsistent and divergent 'facts', produce deeper misunderstanding regarding the question of the etiology of autism. Therefore, as a result of such approach, we are faced with the definition of autism as a pervasive developmental disorder of different etiology but same appearances. ${ }^{26}$ This approach to defining autism creates more confusion in understanding autism and in that respect offers greater opportunity to a variety of therapeutic approaches all of them being justified.

If we accept the 'facts' of the genetic basis of autism, then we can identify a very small number of autistic cases, as observed by Zepf $\mathrm{S}$ and Zepf FD. ${ }^{27}$ Thus, a review of a conducted researches shows that chromosomal aberrations were found in less than $6 \%$ of autistic childre ${ }^{28}$ and also a single gene that could be responsible for the occurrence of autism was not identified. ${ }^{29}$

Equally important is the observation that, in addition to using the same methodological approaches, we encounter inconsistent 'facts' of such researches. So, in relation to very often cited results, ${ }^{30,31}$ which indicated a significantly higher incidence of autism in identical twins compared to fraternal ones, new repeated studies. ${ }^{32-35}$ which included the same methodological approaches, did not confirm the previous results.

This effort to remain within the frame of 'facts' does not give us much hope in a positive therapeutic approach to autism. To that extent, all different 'facts' about organic causes of autism do not provide us with what we needed for the development of an adequate therapeutic approach. Therefore, I agree with the observation by Rapina ${ }^{36}$ that all these organic findings suggest nothing about any clear coherent anatomical structures or patho-physiological basis as well as any biological diagnostic test that we can use as a measure for establishing the diagnosis of autism.

This is not to dismiss and diminish the value of the 'facts', but I think that in accordance with the above definition of autism as a disease of different etiology and similar appearance, we should not focus on the search for new and new 'facts', but to explore a common process that all these different precipitating factors unifies in the same autistic appearance. From my point of view, we have to make differences between causes and precipitating conditions which may produce autistic symptoms. With such approach all these 'facts' of different causes of autism could be understand as precipitating conditions having influence on a unique process which produces autistic symptoms.

\section{Splitting in professional approaches: Organic and psy- chic autism}

The problem of splitting, regarding the question of etiology of autism, may also be recognized equally in the professional environment. In an attempt to get closer to the existing psychiatric nomenclature autism is most often defined as a psychosis that was explained by autistic difficulties in establishing relationships with the outside world and weaknesses of their ego. ${ }^{37}$ However, the concept of child psychogenic psychoses, which includes autism, for most psychiatrics as recognized by Tustin, ${ }^{38}$ represents a controversial concept. These psychiatrics, in descriptions of autistic disorder, primarily emphasize the cognitive deficit of these children as the proof of organic base of autism with which they explain developmental difficulties of autistic children.

This problem is avoided by some authors who make compromise in the way that in psychotherapeutic approach they use some psychological concepts, but in their presentations of their positive psychotherapeutic results they speak mainly of the role of minimal cerebral dysfunctions, metabolic disbalances or predispositions instead of the influence of some psychic mechanisms to which they therapeutically acted.

In an attempt to comply with scientific trends and to avoid the question about organic or psych etiology of autism, Tustin ${ }^{39}$ introduced two types of autism: first, 'organic autism' understood as a consequence of registered brain damages or sensory deficits and second, 'psychogenic autism' understood as consequences of early traumas of separation experiences in children who do not show signs of organic pathology, i.e. in whom the signs of organic pathology were not registered. 
However, significant is Tustin's remark ${ }^{38}$ that by comparing these two (with and without organic signs) groups of autistic children it is difficult to recognize differences between them, because both groups in therapy process manifest similar behavioral characteristics, namely they do not differ in the use of psychological mechanisms.

There are other similar observations which speak in favour of Tustin's statement. Thus she in the review of successful psychotherapy with autistic children in whom were registered organic pathology recognized that these children used the same psychological defence mechanisms as well as autistic children in whom were not registered signs of organic pathology. The same noted ${ }^{40}$ in the way that there are no differences in the behaviour between autistic children with and without neurologic (organic) dysfunction.

The insurmountable problem of splitting has also received other appearances. Thus, some other authors, ${ }^{36,38}$ in order to avoid confusion associated with the problem of etiology of autism and problem of appropriate psychotherapeutic approaches, recommended that the question of etiology should not be connected with the question of treatment. Similarly, Hallett and Viren, ${ }^{41}$ Harshman $^{42}$ suggest that, at least in the first step of psychotherapy, questions of etiology should be ignored and that in the determination of autism its phenomenological features should be used. As a result, they suggest autism to be defined as a developmental disorder marked by failure in the child's development of psychosocial skills.

The complexity of the issue of the etiology of autism is expressed in the 'interaction' model of autism, which Alvarez ${ }^{36}$ connects with the theory of chaos. As the base of this model the appearance of autism can be triggered by very small and undistinguished causes ('butterfly effect'), which can later 'without any apparent reason' lead to autistic manifestations.

From all of that mentioned about the existence of the same psychic mechanism in both (with and without sings) groups of autistic children, we may conclude that as the base of autistic symptom-pathology there is an unique process by which different precipitating conditions may take form of the same autistic symptoms. The observation itself that the same (clinical) pictures may be the result of different precipitating conditions and that different phenomena can be reduced to the same phenomenology indicates that there is a unique process which needs to be subject of investigation in the autistic field.

In relation to the attitudes of some previously mentioned authors that the questions of etiology should be avoided at least at beginning of therapy, I must again emphasize that for a successful and appropriate psychotherapeutic approach we need to have a clear concept of the etiology of autism.

\section{Overcoming the problem of the splitting}

In the first part of the debate I mentioned the unacceptable definition of autism as a disorder of different causes and similar appearances. In this part, the emphasis was placed on the need to recognize a unique process that shapes the diversity of organic precipitating conditions in the same appearance of autistic symptoms. In the second part, the existence of the same psychological mechanisms in autistic children, regardless of the appearance or not of organic signs, was recognized. It was also recognized that a therapeutic impact on these same mechanisms have brought positive therapeutic changes in both groups of autistic children.

All of these previous observations speak in favour of the existence of a unique process that participates in a basic autistic symptoms formation. Therefore to overcome this existing dichotomy between organic and psychic etiological concepts of autism it is important to focus on identifying and understanding such a unique process. The possibilities to resolve this problem I found in contemporary studies of early child development in which special contributions were given by intersubjectivists.

Intersubjectivists contributions to a new understanding of autism as well as a new approach to psychotherapy of autistic children have been recognized by other authors. ${ }^{36,38,43,44}$ Thus, Alvarez ${ }^{36}$ speaking about 'controversy of autism' indicated that the organic and psychological approaches that were placed on the divergent positions with time have become closer. This gradual changes in regard to the early divergent position of the British psychoanalytic theory of object relations and many other 'organic' concepts became possible whit the 'bridge' built between the two sides by the contributions of new research results of intersubjectivists, primarily of Daniel Stern. ${ }^{45}$

In regard to these observations, it is important to look at significant contributions of these intersubjectivist authors. Special contributions by intersubjectivists ${ }^{45-51}$ were their approach in which they have placed the early child interaction with the mother in the centre of investigations of child's development. In their investigations they recognized the importance of children 'matching with' their mothers as a key experience for later development of their psychosocial skills. In this way, the success of the development of the child's social skills is associated with the specificity of the mother-child relationship in which we can recognize a specific process responsible for the development of the child's social features.

The starting point of such an approach in investigations of children's development we can find in the observation that newborns, very shortly after their birth begin to imitate some mothers' grimaces and facial expressions as the first mode of interaction and communication with them. ${ }^{52}$ By this observation it has been noticed that a child begins very early to communicate with his mother and that this imitative communication with the mother represents for him a prototype of all future social relations. Therefore, these early interactions with the mother were recognized as a basis for the child psychosocial development. In investigations of this early experience of communication with (matching with) mothers a special importance was given to children innate ability of imitation ('neonatal imitation') as a basis for the development of their 'primary intersubjectivity', ${ }^{46}$ i.e. an experiential base for the later development of their social relation capacities.

In line with these observations, the failure in the later child's development of social abilities may be attributed to a failure in establishing the earliest child's interactions with the mother. In this developmental failure from intersubjectivists' point of view the main role have problems connected with the child's abilities of imitation. These were particularly recognized in autistic children who in contrast to other typical children do not possess spontaneous but only mechanical type of imitation. ${ }^{53}$

These problems in the development of autistic children were recognized in their later failure to develop the 'theory of mind' ${ }^{53,54}$ This failure is evident in their disability to recognize and understand the subjectivity of others. It is this 'theory of mind' that is used to explain the inability of autistic individuals to develop an empathic relation with their environment.

In investigating the cause of such unfavourable (adverse) psychosocial development a particular attention is focused on the problem of neonatal imitation. Such approach has directed some authors to study brain structures responsible for imitative behaviour formations. This 
led to the development of new organic theories directed to pathology of subcortical structures ${ }^{55}$ as well as other cortical structures, such as the region of 'mirror neurons'. ${ }^{56}$

Such approach brings us back at the beginning of the previously mentioned constraint, i.e. in the area of many different organic theories associated with different brain structures responsible for the failure of the psychosocial child's development and the appearance of autism. Furthermore, with this approach the question of the meaning and the role of the influence of mother-child interactions on development of those mental structures important in the child's development of psychosocial skills have remained beyond investigations. Thus, a search for specific brain structures, which are responsible for the underdevelopment of the child's imitative behaviour in relations with the mother and for the failure in his later psychosocial development, acquired a special role in investigations instead of the investigation of interactive specificities in mother-child communication. In this way it was neglected the question of the role of types and qualities of these mother-child relations in the child's later development of social functioning abilities.

In relation to the observed problem of the negligence of the importance of early mother-child interactions on a child's development, a particularly important contribution was obtained from Stern ${ }^{45}$ who went a step further by placing the mother-child interaction in the centre of his investigations. Actually, he made a significant progress by introducing the concept 'change with' instead of the concept 'matching with'. In relation to the investigations of 'matching with' mother based on the child's abilities to imitate his mother's facial and other forms of behaviour as a type of one-way communication, Stern has given importance to the mother-child interaction as a double guided or two-way communication. In this way the mutual interaction 'changing with' represents the basis of mother-child 'affective attunement' important in development of the child psychosocial abilities. With this approach, except for the maternal external behaviour as a model of child imitation, a particular importance has been given to the role of internal maternal states in interaction with the child. By introducing this mutual process of 'changing with' instead of 'matching with', the importance has been given to the mother's affective state instead of her manifested behaviour during the interaction with her child.

Thus 'changing with' can be described as micro-dynamic shifts in the mother-child interactions which during the time shape changes within both of them. Thus, mother and child automatically and without awareness change their affective states in a way that each of this couple feels what has been experienced in the other. Stern's concept indicates that through mutual imitation and reproduction of facial expressions, movements and vocalizations, mother and child reproduce in each other sensory conditions, which are the basis for the child's development of 'vitality contours'. This concept from my point of view has a special meaning for understanding the genesis of autism that I spoke about in my lectures in Pula ${ }^{57}$ and in Dubrovnik. ${ }^{58}$

Exactly these experiences of mother-child interactions in establishing and maintaining new affective states of 'vitality' represent for Stern a basis for building different levels of the self (initial, core, inter-subjective and verbal) during this early developmental course. Through his representation of gradual development of self, Stern has clearly indicated that mother-child interactions have an important role in formation of those basic layers of psychic structures significant in later psychosocial child's development.

This Stern's understanding of 'affective attunement' as a mutual interaction ('changing with') between the mother and the child in which they interchange and regulate each other's affective states in contrast to the child's ability to imitate ('matching with') aspects of maternal behaviour, gives us a new dimension of understanding the meaning of early interactions in a later child development. In this way the early child development is understood as a two-direction process in which two actors participate, contrary to the understanding of this early development as one-directed process in which only the child more or less successfully imitates, i.e. responds to the mother's stimuli. Hobson ${ }^{59}$ illustrates these interactions between the mother and the child, significant in child's emotional and cognitive development, as a dance in which an adult leads a child. In this mother's leading of the child in line with Stern's concept of 'changed with' includes not only maternal overt behavioral aspects that can be imitated, but also her internal affective state.

In this context it is important to mention the contribution by Hob$\operatorname{son}^{59}$ who expanded the importance of the experience of the mutual mother-child interactions from the child development of social to cognitive abilities. In this way, it has been made a departure from the generally accepted view that the cognitive development is only in the function of brain maturation. It is this generally accepted view that is used in proving the organic bases of autism. Thus for many authors a large percentage of autistic children with lower cognitive level have been used as a proof of the organic basis of autism.

Therefore, today we very often encounter such arguments about an organic basis of autism. However, if it were so then, in the previously presented case of autistic girl Martine, it would not have been possible to achieve significant changes in her general autistic state and especially in her cognitive function from severe mental retardation to the level of lower average. On the contrary, the changes in her ability to build mutual relationships with others led gradually to the development of higher and higher mental structures. My observation is consistent with the Kanner's observation ${ }^{60}$ that low level of cognitive functioning which is often present in autistic children may be recognized only as manifestation of the primary problem of autism, i.e. 'disturbances of affective contact'.

This understanding is in the spirit of Piaget's concept of interactionism $^{61}$ in which the cognitive development is determined by the success of child's interactions with his environment through assimilation-accommodation processes. This commonly accepted notion that a failure in the development of cognitive skills is the result of the damage and pathology of brain structure is complemented by the understanding that regardless existence of any organic pathology cognitive structures cannot develop outside context of child's interactions with his environment. Therefore, autistic children's failure in the development of cognitive structures should be seen from this point of view as a result of their primary problem, i.e. of their basic difficulty in building mutual relationships with others.

After the presentation of intersubjectivists' specificities in understanding the early child development, it is necessary to return at the beginning of this presentation, i.e. the problem of splitting in the concepts of autistic etiology. As I pointed out earlier, intersubjectivists' contributions, especially by Stern and Hobson, give us possibilities to overcome the problem of splitting and to understand the genesis of autism. In this way they shed a new light on a psychotherapeutic approach to autism.

The first intersubjectivists' contribution, which from my point of view has to be singled out, is their approach to investigation of the child's development in which the quality of the early interaction between the mother and the child is placed in the centre of their investigation. It was the investigation of child's development of the 'primary intersubjectivity' 45 that has raised awareness of the importance of the 
early mother-child interactions for the later development of child's social skills. From the standpoint of the problem of splitting in understanding the autistic etiology, particularly important observations were obtained from intersubjectivists' observations that the quality of early child's interactions with the mother is the basis for the formation of mental structures important in the subsequent his emotional, cognitive and social development. Therefore, pervasive developmental disorder in autistic child may be understood as the consequence of failure in the formation of these mental structures which were not or not good enough developed during his early interactions with mothers.

The second important contribution, which is primary associated with Stern's work, is to the notion that the interaction between the mother and the child is a two-way process in which, besides the child's ability to imitate, which for many intersubjectivists represents the main subject of investigations, the mother's ability to participate in these affective interchanges ('affective attunement') plays the same important role in the interactive process of primary mental structure building.

In this way, the failure of early emotional, social and cognitive development, which is found in autistic children, can be understood as a consequence of the failure of early affective mother-child interactions in which both participants have an important contribution. Thus, on the one hand, the failure of this development may be explained by some different congenital organic child's limitations that may interfere with his spontaneous imitation abilities as well as with abilities to participate in affective interactions with the mother. On the other hand, the failure of this development can be explained by affective inability or unpreparedness of the mother to participate in the 'affective attunement' due to various reasons, such as her own personality characteristics associated with acceptance of her maternal role or specific developmental child's requirements and equally her difficulties in coping and overcoming child problems to participate in the relationship with her.

It has been already recognized many times by various authors the limitations of depressed mothers in the process of construction of primary mental structures important in the child's emotional, social and cognitive development. However, less present are the observations about the meaning of mothers participation in the process of the early development when they are faced with the child's difficulties in establishing and maintaining affective relationships with her due to different (organic-psychic; innate-acquired) reasons.

In different ways of mother's affective acceptance and overcoming of child's difficulties in establishing and maintaining mutual interactions with her, we may recognize differences that may determine a later success of the child affective, social and cognitive development. This observation is in line with Acquarone, ${ }^{62}$ who observed that helping mothers in establishing and maintaining adequate affective interactions with their children who show some difficulties in communication may contribute to positive overcoming of these initial signs of failure in the early development that she named pre-autism.

This new understanding of mothers' roles in early interactions with their children shed a new light on Betlehaim's concept of 'refrigerator mothers'. In the situation when the mother is faced with difficulties of her child, who instead of expected forms of behaviour shows limited or inadequate ones, it may be expected that she will show 'astonished, upset, anxious, frozen and immobilized' states. These mother's states may determine the quality of her further interactions with the child and may become, through the process of 'changing with', the base for bad affective communications with her child. In this way she may influence negatively on the child's further psychosocial development. Such mother's conditions in accordance with the Stern's observations do not ensure the development of such relationships that can offer the development of 'vitality contours' and thus do not initiate the child's development towards the world of objects.

Regarding the previously presented observations we may conclude that autism is a pervasive disorder of affective, social and cognitive development which is determined by the failure of the formation of primary mental structures through not good enough established and maintained primary mutual relationships with the mother. This failure may be understood as a consequence:

a. on one hand, of child's innate or later obtained organic and psychic limitations recognized in his difficulties in establishing and maintaining mutual interactions with the mother as well as

b. on the other hand, of maternal affective limitations in participating in this process of mutual interactions due to her difficulties in confrontation with child's developmental tasks as well as child's difficulties in dealing with these developmental tasks.

\section{New possibilities in psychoanalytic psychotherapy with autistic children}

At the end of this presentation it may be concluded that these new intersubjectivists findings, which suggest that the quality of the interaction between the mother and the child has significant meaning in his development of primary mental structures and psychosocial abilities, may serve as 'bridge' which connects two opposite sides (concepts) of autistic etiology. Figuratively speaking, this bridge connects two opposite sides of the same river called Autism. So we can say that there are two (organic and psychic) banks of the same river from which we may differently observe its same flow. Therefore, this bridge can help us meet all richness of its appearances from different positions and discover as well as create the way of its optimal free low.

This bridge may help us to explain how different child's organic states and conditions, discussed in a variety of organic genetic, neurological, metabolic and other theories of autism, may be reduced to an identical clinical picture of autism. This identical clinical picture of autism, in relation to the diversity of organic pathology expressed in a multitude of organic based theories of autism, may be understood within the unique context of early child-mother interactions. Just through the understanding of the specific uniqueness of certain types of these interactions, we may conceive how different precipitating child's conditions may have similar appearances in autistic symptomatology. Therefore, through investigations of particular modes or types of mutual mother-child interactions, especially those connected with maternal affective coping and mastery of individual child's difficulties in his development, we may discover a lot of particularities of autistic genesis.

This bridge, built on the knowledge of the meaning of certain aspects of interactions with the mother in a child's psychosocial development, may also serve to explain the fact that there are the same psychological mechanisms in both groups of autistic children with and without organic signs, and that dealing with these same mechanisms we may achieve significant positive changes regarding autistic symptoms in both groups of autistic children. Just these positive results obtained by using the same therapeutic approaches in both groups speak in favour of the existence of a single process that occurs within the mother-child interaction. Through revealing failing aspects of these interactions, we may discover many reasons for unfavourable child development which may lead to autism. 
Thus, discovering positive and negative meanings of certain aspects of mutual mother-child interactions for the child's development of primary mental structures, which are significant in his psychosocial development, we open up the possibility to discover many new therapeutic approaches with autistic children. Namely, by recognizing positive contributions of certain forms of interactions with mothers in the child psychosocial development, we may construct, through their revival in the therapeutic milieu, those experiences which are important in the construction of the child's mental structures whose underdevelopment or absence might have led to autism.

As to the initial question about the possibility of psychoanalytic psychotherapy of autism and with it connected limitation of the application of psychotherapeutic approaches with autistic children, I would like to emphasize that just knowledge obtained through my psychotherapy with eight autistic children helped me to overcome this, for me the first and the most important constraint, based on generally accepted understanding of the organic basis of autism. This contemporary state determined by diverse and mutually inconsistent theories of organic etiology of autism pushes psychological theories of autism in the background and thus the possibility of using psychotherapy with autistic children. The problem I have defined as the problem of splitting in contemporary scientific and professional environment. ${ }^{13}$

In addition to my own psychotherapeutic knowledge acquired with eight autistic children, in results of intersubjectivists' investigations I found the additional confirmation for overcoming previously mentioned constraint in regard to applying psychotherapy with autistic children. In their results I found confirmation of the existence of psychological factors in the occurrence of autism. This knowledge led me further to develop psychogenic concepts of autism and in accordance with it the new therapeutic approach to autistic children. The recognition of the importance of early dyadic interactions with the mother in the child's development of the primary mental structures helped me construct 'developmental model of autism'. Through introduction of this developmental model the meaning of early (traumatic) separation experiences in normal and pathological development of object relations was placed into the background of a therapists' interest. This new approach in understanding the genesis of autism made step forward (further) from those of Tustin, Meltzer and Mahler, who have had great influence on many contemporary psychotherapeutic approaches to autistic children. These new possibilities and differences in relation to concepts of previous mentioned authors were presented at congresses in Zagreb. ${ }^{63}$

By this 'developmental model' of autism changes in the psychotherapeutic approach have been made possible. Thus leaving the psychoanalytic 'traumatic model' of autism, in which primary emphasis is given to the early traumatic (separation) experience and then introducing the 'developmental model' of autism, in which the emphasis is given to the mental structures, development in regard to establishing relations with objects of outside world led to changes in the therapeutic approach. Instead of mastering, i.e. reconstruction of traumatic experiences, which are holders of delays in the object relation development, the new therapeutic task has become building, i.e. construction of those mental structures important in the process of object relations whose developmental failure could cause autism. By this it was emphasized that the new role of the therapist in a therapy with the autistic children. His task became creating therapeutic conditions that would make possible those affective experiences important in the child development of those mental structures needed for overcoming his developmental delay. These created structures, as the bearers of a child's ability to cope with and work through separation experience, are important in the development of object relations, i.e. in the development of affective contacts with his environment.
The next step in the development of my concept of autism was determined by the question which specific experience in interaction with autistic child may have positive significance in the formation of primary mental structures and at same time which relationships revived in a therapy may overcome delays in the child's object relations development. During the psychotherapeutic work, which I have already presented on congress in Pula, ${ }^{55} \mathrm{I}$ realized that in the construction of primary mental structures, which are important in the development of object relations, a particularly important role has an early narcissistic experience of integrating partial sensory-motor experiences in the unique experience of the child's self. By this knowledge a vital step forward was made in the understanding of the child's development in which there is a mutual relationship between narcissistic and objective lines of development that represent different understanding in contrast to Kohut's ${ }^{64,65}$ self psychology in which these two developmental lines are understood as separated, what I spoke about earlier on congress in Dubrovnik. ${ }^{56}$

At the end of this presentation it is important to emphasise that these new findings on the child development occurred through therapeutic experiences with autistic children are not placed on the opposite side of the existing scientific knowledge obtained through children's observation in the framework of academic (developmental) psychology, but they only require the development of new forms of investigation. This new investigation should be focused on detecting the specificities of mutual mother-child interactions as well as their meaning for the development of certain aspects of child's psychosocial abilities. Therefore, it is necessary to overcome till now the existing 'splitting' in approaches to investigations in which are examined, on one hand, the presence of certain organic pathological signs in a group of autistic children and, on the other hand, the specificities of personality characteristics of mothers of autistic children. Investigations must be therefore focused on examining their interactive effects. Specifically, it should be emphasized that researches based on linear causality do not lead us to a deeper understanding of autistic development. Therefore, we need investigations that will include the examination of circular causality, i.e. of their mutual interactive effects in the child's development and the occurrence of autism.

In implementation of these new tasks, changes are required in investigation approaches to the child development, where apart from the use of observations of individual manifested behaviours, as it does the academic developmental psychology, the investigation of children's development should also include psychodynamic approach in terms of the use (construct) of the child 'inner experience', without which any understanding of this development cannot be complete. The confirmation of the value of such approach can be found in Stern. ${ }^{45}$

We may conclude that all facts presented in this lecture speak in favour of the understanding that there is no splitting, but on the contrary, correspondence between the therapeutically acquired knowledge and the one acquired through scientific investigations. However, it is necessary to integrate this knowledge and to develop new research approaches which offer a possibility to achieve further advances in the understanding of the child development as well as causes of his failure in the development as it is autism. With such a new approach there are opened possibilities for a better understanding as well as therapeutic approach to autism.

\section{Conclusion}

At the end of this presentation it is necessary to turn again back to the initial observation of the constraint which psychotherapists are faced with in their attempt to realize a psychoanalytic approach in the psychotherapy of autistic children, i.e. the question about the 
possibility of applying psychoanalytic or any other psychotherapeutic approaches in the treatment of autistic children. Based on the previous discussion about the position of psychoanalytic (psychic) concepts in the therapy of autism as well as on positive experiences obtained over twenty years of my psychotherapy with eight autistic children it could be concluded:

i. To find appropriate and therefore successful approach in psychotherapy of autistic children it is absolutely necessary the existence of the concept of psychogenesis of autism. Only on the basis of such knowledge, which clearly defines the content and method of therapeutic approach, it is possible to achieve significant changes in the field of autistic symptomatology.

ii. To realize the set goal, it is necessary to overcome the problem which exists in the modern scientific and professional environment defined as the splitting of concepts about the genesis of autism. Particularly negative meaning has the existence of multitude mutually inconsistent findings on organic causes, which define autism as a disorder of various causes and same appearances. In this way, the problem of understanding autism and finding an appropriate treatment for it has increased. Likewise, artificial divisions of organic and psychic autism should be rejected.

iii. To overcome this problem, significant contributions give us results of intersubjectivists' investigations and their recognitions of the importance of early child relationship with the mother in his success in the psychosocial skills development. With this approach we can understand autism as the failure of those developmental processes determined by some early events in the mother-child interaction which play an important role in the construction of mental structures necessary for the development of object relations.

As a conclusion I would like to single out the observation obtained during my twenty years of therapy with eight autistic children that the application of psychoanalytic psychotherapy with autistic children is not in question, but it requires confrontation with and overcoming of many constraints in scientific and professional fields. In this lecture, the emphasis was on overcoming the first constraint which shed new light on autism and therefore, on a more appropriate approach in the treatment of autistic children.

I hope you agree with my conclusion that psychoanalytic psychotherapy of autism deserves a better position in the contemporary scientific and professional environments, that is, except for its important role in the history of the treatment of autism, it should play an important role in contemporary theory and practice of autism.

\section{Acknowledgments}

None.

\section{Conflicts of interest}

Author declares there are no conflicts of interest.

\section{Funding}

None

\section{References}

1. Ruberman L. Psychotherapy of Children with Pervasive Development Disorders. Am J Psychother. 2002;56(2):262-273.

2. Fonagy P. Research on psychoanalytic psychotherapy with adult. In: Foreword UR et al. (Eds.), Karnac Books Ltd., London, UK. 2004. p.19-27.
3. Autism Europe (AE) Improving quality of life for people with autism

4. Spelic A. Mogucnosti psihoanaliticke psihoterapije autizma: Novi psihoterapijski pristup. In: Gregurek R (Ed.) 'Izazovi psihoterapije u stoljecu uma'. I Hrvatski psihoterapijski kongres. Hrvatska: Zadar. 2008. p.67-67.

5. Spitz RA. Hospitalism; An Inquiry into the Genesis of Psychiatric Conditions in Early Childhood. Psychoanal Study Child. 1945;1:53-74.

6. Klein M. Notes on some schizoid mechanisms. J Psychother Pract Res. 1996;5(2):160-179.

7. Eugene DM. On human symbiosis and the vicissitudes of individuation. Arch Gen Psychiatry. 1969;20(4):490-492.

8. Bowlby J. Attachment. Attachment and Loss. (2nd edn), New York Basic Books, New York, USA. 1969. p.1-326.

9. Spitz RA. The first year of life: a psychoanalytic study of normal and deviant development of object relations. International Universities Press, New York, USA. 1965.

10. Winnicott DW. The maturational processes and and the Facilitating Environment: Studies in the Theory of Emotional Development. Hogarth Press and the Institute of Psycho-Analysis, London, UK. 1965. p.1-182.

11. Spelic A, Koseto M. Preparation of an autistic child for school. Metodicki obzori Pula. 2012;7(2);157-172.

12. Mahler SM, Pine F, Bergman A. Psychological Birth of Humane Infant, Basic Books, New York, USA. 1973

13. Spelic A. Psihoanaliticka psihoterapija autizma danas: Ogranicenja i nove mogucnosti u suvremenom znanstvenom i strucnom okruženju. U: Skodlar B (Ed.). Navezanost (str. 82-96). Združenje psihoterapeutov Slovenije, Ljubljana. 2010

14. Kanner L. Problems of nosology and psychodynamics in early infantile autism. Am J Orthopsychiatry. 1949;19(3):416-426.

15. Naustin Deslauriers. The Empty Fortress: Infantile Autism and the Birth of the Self. Arch Gen Psychiatry. 1967;17(4):510-512.

16. Waters L. Reinforcing the Empty Fortress: an examination of recent research into the treatment of autism Educational Studies. 1990;16(1):3-16.

17. Herbert JD, Sharp IR, Gaudiano BA. Separating Fact from Fiction in the Etiology and Treatment of Autism: A Scientific Review of the Evidence. The Scientific Review of Mental Health Practice. 2002;1(1):23-43.

18. Singh VK, Lin SX, Yang VC. Serological association of measles virus and human herpesvirus-6 with brain autoantibodies in autism. Clin Immunol Immunopathol. 1998;89(1):105-108.

19. Pardo CA, Eberhart CG. The neurobiology of autism. Brain Pathol. 2007;17(4): 434-447.

20. Levin FM, Trevarthen C. Subtle is the Lord. Annuals of Psychoanalysis. 2000;28:105-125.

21. Mesibov GB. Autism. In: Dulbecco R (Ed.) The encyclopaedia of human biology, New York Academic, New York, USA. 1991. p. 505-512.

22. Volkmar FR. Understanding autism. Psychoanalytic Inquiry. 2000;20(5):660-674.

23. Lamb JA, Parr JR, Bailey AJ, et al. Autism: In search of susceptibility genes. Neuromolecular Med. 2002;2(1):11-28.

24. Uhlmann V, Martin CM, Sheils O, et al. Potential viral pathogenic mechanism for new variant inflammatory bowel disease. Mol Pathol. 2002;55(2):84-90

25. Fine SE, Weissman A, Gerdes M, et al. Autism spectrum disorders and symptoms in children with molecularly confirmed 22q11.2 deletion syndrome. J Autism Dev Disord. 2005;35(4):461-470. 
26. Bujas-Petkovic Z. Prevazivni razvojni poremecaji. In: Bujas-Petkovic Z, et al. (Eds.) Poremecaji autisticnog spektra. Skolaska knjiga, Zagreb. 2010. p.39-47.

27. Zepf S, Zepf FD. Autism in Infancy: The Psychodynamics from a Freudian Viewpoint. Canadian Journal of Psychoanalysis. 2008;16(2):194-223.

28. Bailey A, Le Couteur A, Gottesman I, et al. Autism as a strongly genetic disorder: Evidence from a British twin study. Psychol Med. 1995;25(1):63-77.

29. Rutter M. Autism research: Lessons from the past and prospects for the future. J Autism Dev Disord. 2005;35(2):241-257.

30. Folstein S, Rutter M. Infantile autism: A genetic study of 21 twin pairs J Child Psychol Psychiatry. 1977;18(4):297-321.

31. Bailey A, Le Couteur A, Gottesman I, et al. Autism as a strongly genetic disorder: Evidence from a British twin study. Psychol Med. 1995;25(1):63-77.

32. Croen LA, Grether JK, Selvin S. Descriptive epidemiology of autism in a California population: Who is at risk? J Autism Dev Disord. 2002;32(3):217-224.

33. Hallmayer J, Glasson EJ, Bower C, et al. On the twin risk in autism American Journal of Human Genetics. 2002;71(4):941-946.

34. Hultman CM, Sparen P, Cnattingius S. Perinatal risk factors for infantile autism. Epidemiology. 2002;13(4):417-423.

35. Larsson HJ, Eaton WW, Madsen KM, et al. Risk factors for autism: Perinatal factors, parental psychiatric history, and socioeconomic status. Am J Epidemiol . 2005;161(10):916-925.

36. Rapin I. Autism. New England Journal of Medicine. 1997;337:97-104.

37. Alavarez A. Live Company. Routledge, New York, USA. 1992. p.264.

38. Tustin F .Autistic States in Children. London \& New York: Routledge, UK. 1992.

39. Tustin F. Autism and Childhood Psychosis. The Hogarth Press, London, UK. 1972.

40. Volkmar FR, Lord C, Bailey A, et al. Autism and pervasive developmental disorders. J Child Psychol Psychiatry. 2004;45(1):135-170.

41. Hallett J, Viren D. Making sense of autism. Med Health $R I$. 2005;88(5):143-146.

42. Harshman EJ .Autism: A Cognitive or Behavioral Disorder. Medical Sentinel. 2002;7:126-127.

43. Mori S. The role of the self-object experience in the therapy of an autistic child: from lying at to launching a 'spaceship'. Journal of Child Psychotherapy. 2001; 27(2):159-173.

44. Rhode M. Mirroring, imitation, identification: the sense of self in relation to the mother's internal world. Journal of Child Psychotherapy. 2005;31(1):52-71.

45. Stern DN. The Interpersonal World of the Infant. Basic Books, New York, USA. 1985

46. Trevarthen C. 'Communication and co-operation in early infancy: a description of primary intersubjectivity'. In: Bullowa M (Ed.) Before Speech. Cambridge University Press, Cambridge, USA. 1979.
47. Trevarthen $\mathrm{C}$. The concept and foundations of infant intersubjectivity. In: Braten S (Ed.) Intersubjective Communication and Emotion in Early Ontogeny. University Press, Cambridge, England. 1998.

48. Trevarthen C, Aitken KJ. Infant intersubjectivity: research, theory, and clinical applications. J Child Psychol Psychiatry. 2001;42(1):3-48.

49. Trevarthen C.Emotions in infancy: regulators of contacts and relationships with persons. In Scherer, K.I., Ekman P (Ed.) Approaches to Emotion, Hillsdale, Erlbaum, New York, USA. 1984.

50. Beebe B, Beatrice, Frank M, et al. Infant research and adult treatment. Analytic Press, New Jersey, USA. 2002. p.55-57.

51. Hobson RP, Lee A, Brown R. Autism and congenital blindness. J Autism Dev Disord. 1999;29(1):45-56.

52. Kugiumutzakis G. Neonatal imitation in the intersubjective companion space. In: Braten S (Ed.) Inter subjective Communication and Emotion in Early Ontogeny. Cambridge University Press, Cambridge, England. 1988.

53. Blackwell B. recursors to a theory of mind: Understanding attention in others. In: Whiten A (Ed.) Natural theories of mind: Evolution, development and simulation of everyday mindreading. Basil Blackwell, Oxford, USA. 1991. p. 233-251.

54. Baron-Cohen S, Leslie AM, Frith U. Does the autistic child have a "theory of mind"? Cognition. 1985; 21(1):37-46.

55. Baron-Cohen S, Ring HA, Bullmore ET, et al. The amygdala theory of autism. Neurosci Biobehav Rev. 2000;24(3):355-364.

56. Rizzolatti G, Arbib MA. Language within our grasp. Trends Neurosci. 1998;21(5):188-194.

57. Spelic A. Primarni narcizam i geneza autizma. III Interdisciplinarni simpozij o ranom razvoju i komunikaciji. Hrvatska; Pula/Motovun. 2010;16-19.06.2010.

58. Spelic A. The genesis of autism in the light of the concept of primary narcissism. XVII International Congress for the Psychological Treatments of the Schozophrenias and other Psychosis - 'Psychological Therapies for Psychosis in the 21st Century-Influencing Brain, Mind and Society'. Croatia Dubrovnik. 2011.

59. Hobson P. The Cradle of Thought: Exploring the Origins of Thinking. Macmillan, London, UK. 2002. p.320.

60. Kanner L. Autistic disturbances of affective contact. Acta Paedopsychiatr. 1968;35(4):100-136.

61. Piaget J. The Psychology of Intelligence. Routledge and Kegan Paul, London, UK. 1947.

62. Alonim AH. Signs of Autism in infants: Recognition and early intervention. Karnac Books, London, UK. 2007.

63. Spelic A. Od traumatskog do razvojnog koncepta autizma. II Hrvatski psihoterapijski kongres. Hrvatska; Zagreb. 2013;21. 23.02.2013.

64. Kohut. The Analysis of the Self: A Systematic Approach to the Psychoanalytic Treatment of Narcissistic Personality Disorders. International Universities Press, New York, USA. 1971. p.384.

65. Meltzer D. Explorations in autism. Clunie Press, Perth, Australia. 1975 